\title{
Integrated Cross-Sectional Multiplex Serosurveillance of IgG Antibody Responses to Parasitic Diseases and Vaccines in Coastal Kenya
}

\author{
Sammy M. Njenga, ${ }^{1 *}$ Henry M. Kanyi, ${ }^{1}$ Benjamin F. Arnold, ${ }^{2}$ Sultani H. Matendechero, ${ }^{3}$ Joyce K. Onsongo, ${ }^{4}$ Kimberly Y. Won, ${ }^{5}$ \\ and Jeffrey W. Priest ${ }^{6}$ \\ ${ }^{1}$ Eastern and Southern Africa Centre of International Parasite Control, Kenya Medical Research Institute, Nairobi, Kenya; ${ }^{2}$ Francis I. Proctor \\ Foundation, University of California, San Francisco, California; ${ }^{3}$ Department of Preventive and Promotive Services, Neglected Tropical Diseases \\ Programme, Ministry of Health, Nairobi, Kenya; ${ }^{4}$ World Health Organization Country Office, Nairobi, Kenya; ${ }^{5}$ Division of Parasitic Diseases and \\ Malaria, Centers for Disease Control and Prevention, Atlanta, Georgia; ${ }^{6}$ Division of Foodborne, Waterborne and Environmental Diseases, Centers \\ for Disease Control and Prevention, Atlanta, Georgia
}

\begin{abstract}
Accurate and cost-effective identification of areas where co-endemic infections occur would enable public health managers to identify opportunities for implementation of integrated control programs. Dried blood spots collected during cross-sectional lymphatic filariasis surveys in coastal Kenya were used for exploratory integrated detection of IgG antibodies against antigens from several parasitic infections (Wuchereria bancrofti, Schistosoma mansoni, Plasmodium spp., Ascaris lumbricoides, and Strongyloides stercoralis) as well as for detection of responses to immunizing agents used against vaccine-preventable diseases (VPDs) (measles, diphtheria, and tetanus) using a multiplex bead assay (MBA) platform. High heterogeneity was observed in antibody responses by pathogen and antigen across the sentinel sites. Antibody seroprevalence against filarial antigens were generally higher in Ndau Island $(P<0.0001)$, which also had the highest prevalence of filarial antigenemia compared with other communities. Antibody responses to the Plasmodium species antigens circumsporozoite protein (CSP) and merozoite surface protein-1 (MSP-1) 19 were higher in Kilifi and Kwale counties, with Jaribuni community showing higher overall mean seroprevalence $(P<0.0001)$. Kimorigo community in Taita-Taveta County was the only area where antibody responses against $S$. mansoni Sm 25 recombinant antigen were detected. Seroprevalence rates to Strongyloides antigen NIE ranged between $3 \%$ and 26\%, and there was high heterogeneity in immune responses against an Ascaris antigen among the study communities. Differences were observed between communities in terms of seroprevalence to VPDs. Seroprotection to tetanus was generally lower in Kwale County than in other counties. This study has demonstrated that MBA holds promise for rapid integrated monitoring of trends of infections of public health importance in endemic areas.
\end{abstract}

\section{INTRODUCTION}

Several major infectious diseases occur in sub-Saharan Africa including malaria and neglected tropical diseases (NTDs), which are particularly common among resource-poor populations. ${ }^{1-3}$ Consequently, several of these diseases are co-endemic and past studies in the region have identified subgroups that are polyparasitized with soil-transmitted helminth (STH) infections, filarial parasites, and malaria. ${ }^{4-6}$ Lymphatic filariasis (LF) caused by Wuchereria bancrofti is principally confined to the coastal region of Kenya where ecological factors are suitable for its transmission ${ }^{7}$; the disease cooccurs with other infectious diseases such as STH infections, schistosomiasis, lower respiratory infections, and malaria. ${ }^{8-10}$

In the past, lack of resources often compounded by competing health priorities in sub-Saharan Africa has led to insufficient commitments to control NTDs. More recently, however, implementation of successful public-private partnerships for health have availed resources for control and/or elimination of NTDs as public health problems. In 2000, the WHO Global Programme to Eliminate Lymphatic Filariasis (GPELF), launched in response to World Health Assembly resolution WHA50.29, urged member states to initiate activities to eliminate LF as a public health problem, a goal subsequently targeted for $2020 .{ }^{11}$ Community-wide mass drug administration (MDA) of antifilarial drugs for 4-6 years is recommended for LF

${ }^{*}$ Address correspondence to Sammy M. Njenga, Eastern and Southern Africa Centre of International Parasite Control, Kenya Medical Research Institute, Mbagathi Rd., P.O. Box 54840-00200, Nairobi 0200, Kenya. E-mail: sammynjenga@gmail.com elimination, and modeling studies have estimated adequate treatment coverage to be at least $65 \%$ of total population in endemic areas. ${ }^{12,13}$ Substantial progress has been made toward elimination of LF, with Togo being the first country in subSaharan Africa to be recognized by the WHO for eliminating the disease as a public health problem. ${ }^{14,15}$ The Kenyan Ministry of Health launched an LF elimination program in 2002, but the program did not sustain MDA campaigns annually as per GPELF recommendations. ${ }^{16,17}$ In 2015, the Ministry of Health successfully appealed to the WHO Regional Office for Africa and other partners for support to reestablish annual MDA campaigns. Subsequently, the WHO Country Office in Nairobi, Kenya, selected the Eastern and Southern Africa Centre of International Parasitic Control (ESACIPAC), which is part of the Kenya Medical Research Institute (KEMRI), to conduct a comprehensive epidemiological assessment of LF infection before restarting MDA.

Antibody levels can provide valuable information about exposure to infections and, thus, can be helpful for characterizing pathogen transmission dynamics. ${ }^{18}$ Because parasite antigens are generally known to elicit an IgG response that can be detected for a long period of time, serological analysis of young children could provide an estimate of more recent exposure. ${ }^{19,20}$ A state-of-the-art multiplex bead assay (MBA) serological platform that enables simultaneous detection of antibodies against multiple antigens using a small volume of blood sample dried on filter paper $(10 \mu \mathrm{L}$ dried blood spots [DBS]) has been developed as a tool for integrated biomarker surveys. ${ }^{21-23}$ The MBA has successfully been used to simultaneously measure antibody responses to multiple parasitic 
diseases of public health importance as part of a vaccinepreventable disease (VPD) serological survey in Cambodia. ${ }^{24}$ The platform has also been used to simultaneously assess IgG responses to a panel of malaria antigens. ${ }^{25,26}$ In the present study, the MBA platform was used for multiplex serosurveillance of diseases of public health importance by testing for antibodies against LF and several other parasitic diseases (malaria, schistosomiasis, ascariasis, and strongyloidiasis) as well as seroprevalence to selected VPDs (measles, diphtheria, and tetanus).

\section{MATERIALS AND METHODS}

Study design and samples. The DBS samples used in this study were collected during cross-sectional LF surveys conducted in October 2015 in 10 sentinel sites located across the coastal region in Taita-Taveta, Kwale, Kilifi, Tana River, and Lamu counties. Counties are devolved subnational governments which relate with the national government as distinct administrative units. In this study, a sentinel site is defined as a rural community (village) from which data collection was conducted with the intention of follow-up testing for monitoring and evaluation of the LF elimination program. A detailed description of the 10 sentinel sites and characteristics of the study participants were provided in an earlier report. ${ }^{17}$ Briefly, 300 persons aged 2 years or older in each sentinel site were targeted for the LF survey as recommended in the WHO guidelines. ${ }^{11}$ The middle finger of consenting individuals was cleaned using a cotton ball soaked in $70 \%$ isopropyl alcohol. After drying, the tip of the finger was pricked using a sterile lancet and blood was collected into capillary tubes for detection of circulating filarial antigen (CFA) by immunochromatographic card test (ICT). Additional blood sample from the same prick site was collected onto a filter paper with six extensions, each calibrated to absorb $10 \mu \mathrm{L}$ volume (TropBio Pty Ltd., Queensland, Australia), and then allowed to air-dry for $\geq 4$ hours.

Recombinant antigens and coupling to microsphere beads. Recombinant Schistosoma mansoni glutathione-Stransferase (GST) protein was expressed from pGEX 4T-2 plasmid (GE Healthcare, Piscataway, NJ) and purified as previously described. ${ }^{27}$ Glutathione-S-transferase fusion proteins that included protein sequences from Brugia malayi $\left(\mathrm{Bm}_{3} 3^{22}\right.$ and $\left.\mathrm{Bm} 14^{20}\right)$, Strongyloides stercoralis $\left(\mathrm{NIE}^{28}\right)$, and Plasmodium falciparum 3D7 strain (MSP1 19) were expressed and purified as previously described. A W. bancrofti Wb123GST fusion protein was a kind gift from T. Nutman $(\mathrm{NIH}$, Bethesda, MD). These proteins were coupled to SeroMap beads (Luminex Corp., Austin, TX) using the protein quantities and buffer conditions previously described. ${ }^{24}$ Schistosoma mansoni-native soluble egg antigen (SEA) was a kind gift of $E$. Secor (CDC, Atlanta, GA), and recombinant S. mansoni Sm25 antigen was expressed using the Baculovirus system previously described. ${ }^{30}$ Both proteins were coupled to SeroMap beads using the protein quantities and buffer conditions previously described. ${ }^{30}$

Tetanus toxoid (Massachusetts Biological Laboratories, Boston, MA), diphtheria toxoid from Corynebacterium diphtheriae (List Biological Laboratories, Campbell, CA), and recombinant measles nucleoprotein (MV-N, Meridian Life Sciences, Memphis, TN) ${ }^{31}$ were purchased from commercial sources. Tetanus toxoid was coupled to SeroMap beads as previously described. ${ }^{32}$ Diphtheria toxoid was coupled in buffer containing $50 \mathrm{mM} 2$-(N-morpholinoethanesulfonic acid (MES) at $\mathrm{pH} 5.0$ with $0.85 \% \mathrm{NaCl}$ at a concentration of $60 \mu \mathrm{g}$ of protein per $1.25 \times 10^{7}$ beads in $1 \mathrm{~mL}$ final volume. To decrease background reactivity, measles MV-N was purified by chromatography on a MonoQ HR 5/5 strong anion exchange column (GE Healthcare) before use. Protein $(0.75 \mathrm{mg}$ ) was loaded onto the column at a flow rate of $1 \mathrm{~mL} /$ minute and washed with $4 \mathrm{~mL}$ of $25 \mathrm{mM}$ Tris buffer at $\mathrm{pH}$ 8.0. This was followed by a $10 \mathrm{~mL}$ linear gradient to $0.25 \mathrm{M} \mathrm{NaCl}$ in Tris buffer, and then by a $5 \mathrm{~mL}$ linear gradient to $1 \mathrm{M} \mathrm{NaCl}$ in Tris buffer. Most antibodyreactive MV-N eluted in the high salt fractions between 0.4 and $0.7 \mathrm{M} \mathrm{NaCl}$. These fractions were pooled, concentrated using a Centricon-30 centrifugal filter device (Millipore Corporation, Bedford, MA), and exchanged into a buffer containing $10 \mathrm{mM}$ sodium phosphate with $0.85 \% \mathrm{NaCl}$ at pH 7.2 (phosphatebuffered saline [PBS]). Approximately $115 \mu \mathrm{g}$ of protein was recovered (BCA micro assay, Pierce, Rockford, IL). MonoQ purified MV-N was coupled in a buffer containing $50 \mathrm{mM}$ MES at $\mathrm{pH} 5.0$ with $0.85 \% \mathrm{NaCl}$ at a concentration of $6 \mu \mathrm{g}$ of protein per $1.25 \times 10^{7}$ beads in $1 \mathrm{~mL}$ final volume.

Cloning of the Plasmodium malariae $\mathrm{MSP}_{19}$ coding sequence from China I parasite strain is described elsewhere. ${ }^{33}$ This antigen was coupled to $1.25 \times 10^{7}$ SeroMap beads in $50 \mathrm{mM} \mathrm{MES} \mathrm{buffer} \mathrm{at} \mathrm{pH} 5.0$ with $0.85 \% \mathrm{NaCl}$ at a concentration of $30 \mu \mathrm{g} / \mathrm{mL}$. The glutaraldehyde protocol of Benitez et al. ${ }^{34}$ was used to cross-link a synthetic 20 amino acid peptide ([NANP $]_{5}$-amide) corresponding to the carboxy-terminal repeat of the $P$. falciparum circumsporozoite protein ${ }^{35,36}$ to purified GST protein. Bead coupling conditions for this antigen were identical to those described previously for the P. malariae $\mathrm{MSP}_{19}$ protein.

Purified native hemoglobin $(\mathrm{Hb})$ from Ascaris suum worms was a kind gift from P. Geldhof (Ghent University, Gent, Belgium). ${ }^{37,38}$ This antigen was coupled to $1.25 \times 10^{7}$ SeroMap beads in a PBS buffer ( $\mathrm{pH}$ 7.2) at a concentration of 120 $\mu \mathrm{g} / \mathrm{mL}$.

Multiplex bead assay. One bloodspot from each participant, corresponding to about $10 \mu \mathrm{L}$ of whole blood, was eluted overnight at $4{ }^{\circ} \mathrm{C}$ with $200 \mathrm{~mL}$ of PBS containing $0.05 \%$ Tween-20 and $0.05 \%$ sodium azide (1:40 serum dilution assuming a $50 \%$ hematocrit). A further dilution of $50 \mathrm{~mL}$ of eluate into $450 \mu \mathrm{L}$ of PBS containing $0.5 \%$ casein, $0.3 \%$ Tween-20, $0.02 \%$ sodium azide, $0.5 \%$ polyvinyl alcohol, and $0.8 \%$ polyvinylpyrrolidone (designated as PBN1) with $3 \mu \mathrm{g} / \mathrm{mL}$ Escherichia coli extract was made for a final serum dilution of 1:400. Serum dilutions were centrifuged at a maximum speed to pellet any $E$. coli extract particulates immediately before use. Bloodspot dilutions were assayed in duplicate with antigen-coupled microsphere beads using a Bio-Plex 200 instrument equipped with Bio-Plex Manager 6.1 software (Bio-Rad, Hercules, CA), as previously described. ${ }^{22,24,26}$ The average of the median fluorescent intensity values from the duplicate wells minus the background fluorescence from the buffer-only blank was reported as the "median fluorescence intensity minus background" (MFI-bg). Samples having a coefficient of variation of $>15 \%$ for $\geq 2$ positive responses between the duplicate wells were repeated.

Cutoff determinations. The WHO International Standard reference sera for tetanus (TE-3; $120 \mathrm{IU} / \mathrm{mL}$ ) and diphtheria $(10 / 262 ; 2 \mathrm{IU} / \mathrm{mL})$ purchased from the National Institute for 
Biological Standards and Control (NIBSC) (Potters Bar, Hertfordshire, United Kingdom) were used to identify MFI-bg cutoff values corresponding to immunoprotection. A tetanus TE-3 value of $10 \mathrm{mIU} / \mathrm{mL}^{39,40}$ corresponded to a tetanus toxoid MBA response of $118 \mathrm{MFI}-b g$ units. A diphtheria toxoid MBA response of $4393 \mathrm{MFI}-\mathrm{bg}$ units corresponded to the $0.1 \mathrm{IU} / \mathrm{mL}$ threshold for complete protection, ${ }^{41}$ and an MBA response of $183 \mathrm{MFI}-\mathrm{bg}$ units corresponded to the $0.01 \mathrm{IU} / \mathrm{mL}$ threshold for partial protection. Other studies have shown good concordance between the MBA and "gold standard" formats for tetanus and diphtheria. ${ }^{32,42}$ Although a $\mathrm{WHO}$ reference standard is available for the quantitation of measles virus-neutralizing antibody responses using the whole virus Plaque Reduction Neutralization Test (PRNT) (NIBSC 97/648; $3 \mathrm{lU} / \mathrm{mL}$ ), the standard has not been calibrated for use in ELISA format assays ${ }^{43}$ and our MBA only detects lgG antibodies to the measles MV-N protein. In an independent work using the specific bead set from this study, Coughlin et al. (in preparation) determined that receiver operator characteristic (ROC)-optimized MFI-bg cutoff value of $178 \mathrm{MFI}-$ bg units provided good sensitivity and specificity compared with the "gold standard" PRNT.

Multiplex bead assay cutoff estimates for the $S$. stercoralis NIE assay and for the three LF antigens (Bm33, Bm14, and Wb123) were assigned using a panel of 94 presumed negative sera donated by anonymous adult U.S. citizens with no history of foreign travel. Test values greater than the mean plus three SDs of the presumed negative sample values were considered to be positive. For the $P$. malariae and $P$. falciparum MSP1 19 assays, log-transformed data were used for the mean plus three SD calculation, and the panel used for the $P$. falciparum cutoff included only 65 of the original 94 U.S. adult volunteers. An ROC curve using sera from 41 stool-confirmed, anonymous ascariasis patients, 65 of the adult U.S. citizen volunteers, and sera from 45 anonymous U.S. children was used to identify the cutoff for the Ascaris $\mathrm{Hb}$ MBA. All of the parasitic disease cutoff values were adjusted to account for differences between the instrument used for cutoff determination at the CDC in Atlanta, GA, and the instrument used to assay the Kenyan sample set at KEMRI in Nairobi, Kenya. Two-fold serial dilutions of the same strong positive sera were assayed on both instruments to generate standard curves for cutoff value adjustment. Schistosoma mansoni SEA and Sm25 coupled beads were used in an earlier study, and the adjusted, ROCassigned cutoff values have been reported elsewhere (965 and $38 \mathrm{MFI}-\mathrm{bg}$ units, respectively). ${ }^{30}$

We also estimated seropositivity cutoff points for malaria, $\mathrm{LF}$, and helminth antibody responses using the mean plus three SDs of a seronegative distribution estimated from the study measurements using finite Gaussian mixture models with two components. ${ }^{44}$

Ethical considerations. The study received ethical approval from KEMRI Scientific and Ethics Review Unit (SSC No. 3018). In the study villages, chiefs and assistant chiefs arranged for community mobilization meetings during which the purpose of the survey and procedures to be followed were explained. Written informed consent was obtained from every individual who agreed to participate in this study; parents or legal guardians provided signed informed consent forms on behalf of children younger than 18 years of age. The consent information given to the study participants requested for fingerprick blood to test for LF infection and additional DBS specimen for testing of other common diseases in coastal
Kenya, including vaccine-preventable diseases. All the DBS samples were transported to Nairobi and analyzed in the KEMRI-ESACIPAC laboratory.

Statistical analysis. Mean antibody levels (expressed in MFI-bg units) were analyzed on the $\log _{10}$ scale because of skewness in their distribution. We estimated age-dependent mean antibody levels and seroprevalence for each study community using cross-validated, ensemble machine learning, with a library that included the simple mean, linear models, locally weighted regression (loess), and smoothing splines with 2 to 10 degrees of freedom, selected using 10-fold crossvalidation. ${ }^{18}$ We estimated age-adjusted geometric mean antibody levels and seroprevalence for each community using targeted maximum likelihood estimation with influence curvebased standard errors. ${ }^{18}$ In cases where seroprevalence approached zero, we estimated exact binomial Cls. Analyses were conducted using $R$ version 3.3.1, and full replication files (data and scripts) are available through the Open Science Framework (https://osf.io/taknp).

\section{RESULTS}

Antibody measurements were obtained from 2,837 individuals (range 271-297 per community) (Supplemental Figure 1). Antibody distributions varied by pathogen and antigen, and seropositivity cutoff values for malaria, LF, and helminth antibody responses derived through ROC curve analysis or mean plus three SD calculations were very close to those derived by Gaussian mixture model analysis (Figure 1). We therefore relied on cutoff values derived from the Gaussian mixture model antibody responses for comparability to future studies that may not have access to positive and negative control specimens. Age-dependent patterns and community-level estimates of mean antibody levels and seroprevalence were consistent in their age-dependent patterns and in their community-level ranking (Supplemental Figures 2-6), so we report results based on mean antibody levels in supporting information.

Antifilarial antibody measurements. Individuals who tested positive for LF infection by ICT had higher mean levels of antibody responses against the three recombinant filarial antigens (Supplemental Figure 7). Antibody seroprevalence against all three recombinant filarial antigens were significantly higher in Ndau Island than in other communities, and the difference in seroprevalence in Ndau compared with other communities was markedly greater among persons aged less than 30 years (Figure 2). Antifilarial antibody responses against Bm14 antigen continued to increase with age in all communities. For Wb123, seroprevalence gradually increased with age in Ndau and increased from around the age of 30-35 years in Mwadimu community. Compared with the other communities, Jaribuni had slightly elevated mean antibody responses against $\mathrm{Wb123}$ and Bm33 antigens $(P<$ $0.0001)$, but not for Bm14 antigen $(P=0.08)$. Among the youngest children, quantitative antibody levels differentiated communities more clearly than seroprevalence, owing to high variability in seroprevalence estimates from the small sample sizes in the youngest age strata (Supplemental Figure 8).

Antibody responses to other parasite antigens. Antibody responses to the $P$. falciparum CSP and $\mathrm{MSP}_{-1} 1_{19}$ antigens increased with age in communities in Kilifi and Kwale counties, with higher seroprevalence in Jaribuni community 


\section{Vaccine Preventable}

Measles MV-N

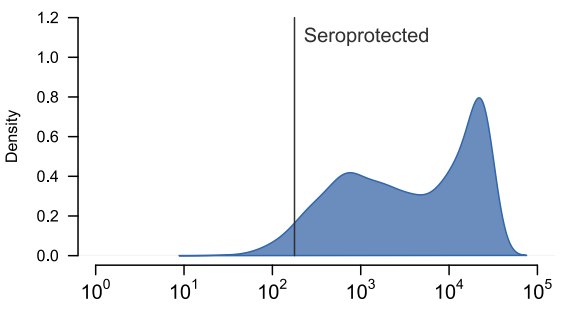

\section{Malaria}

Plasmodium falciparum CSP

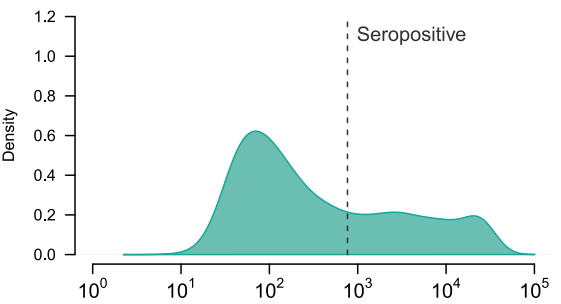

\section{Lymphatic filariasis}

LF Wb123

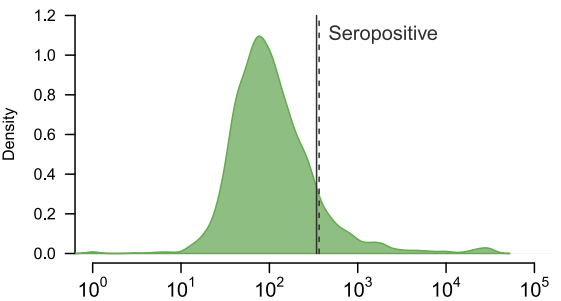

\section{Schistosomiasis}

Schistosoma mansoni SEA

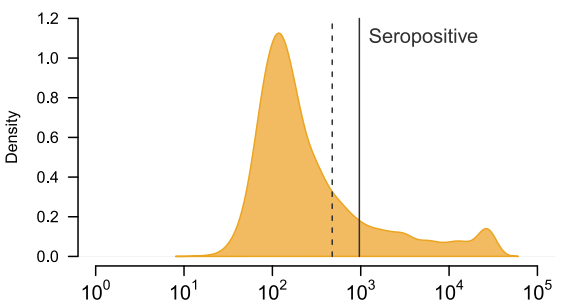

\section{Other helminths}

Strongyloides stercoralis NIE

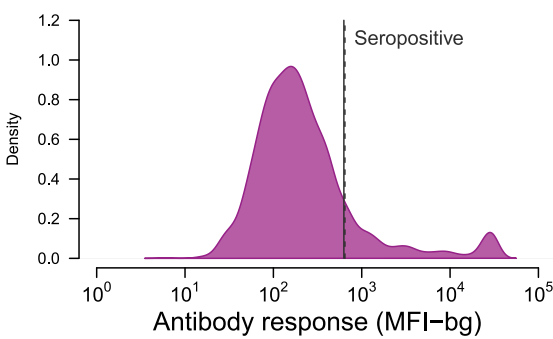

Diphtheria toxoid

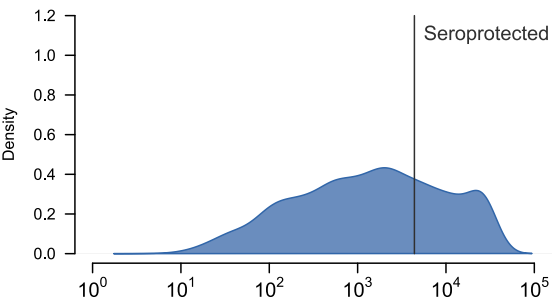

Plasmodium falciparum MSP $-1_{19}$

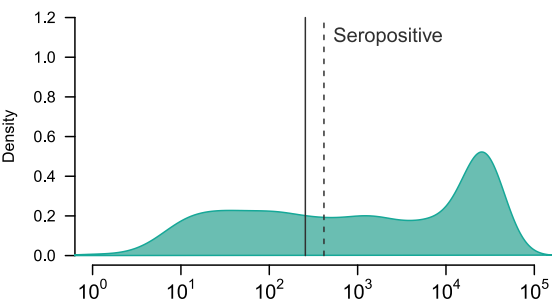

LF Bm14

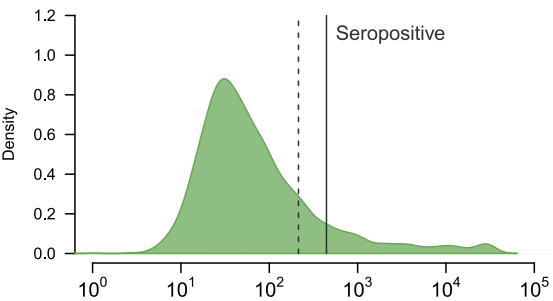

Schistosoma mansoni Sm25

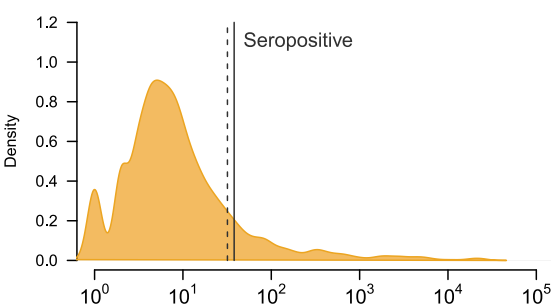

Tetanus toxoid

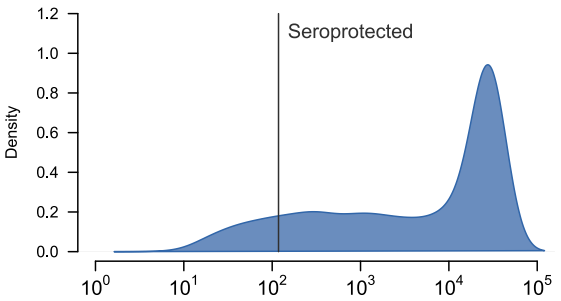

Plasmodium malariae MSP $-1_{19}$

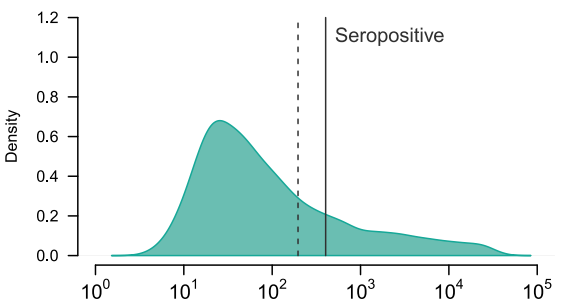

LF Bm33

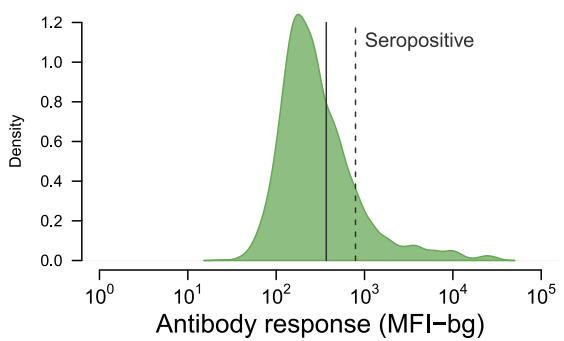

FIGURE 1. Distribution of IgG antibody levels measured in 10 communities in Kenya's coastal region, 2015. Antibody response measured in multiplex using median fluorescence intensity minus background (MFI-bg) units on a BioRad Bio-Plex platform. Seroprotection cutoff points for measles, diphtheria, and tetanus estimated using a standard curve from WHO reference standards. Seropositive cutoff points for other antigens estimated using negative control serum samples (solid) and finite Gaussian mixture models (dashed). There was no negative control cutoff point determined for the Plasmodium falciparum CSP antigen. Supplemental Table 1 includes cutoff values. Created with script: https://osf.io/d9jrc. This figure appears in color at www.ajtmh.org.
Cutoff from standard curve (vaccine prev), or unexposed US adults (others)

Cutoff from Gaussian mixture model 

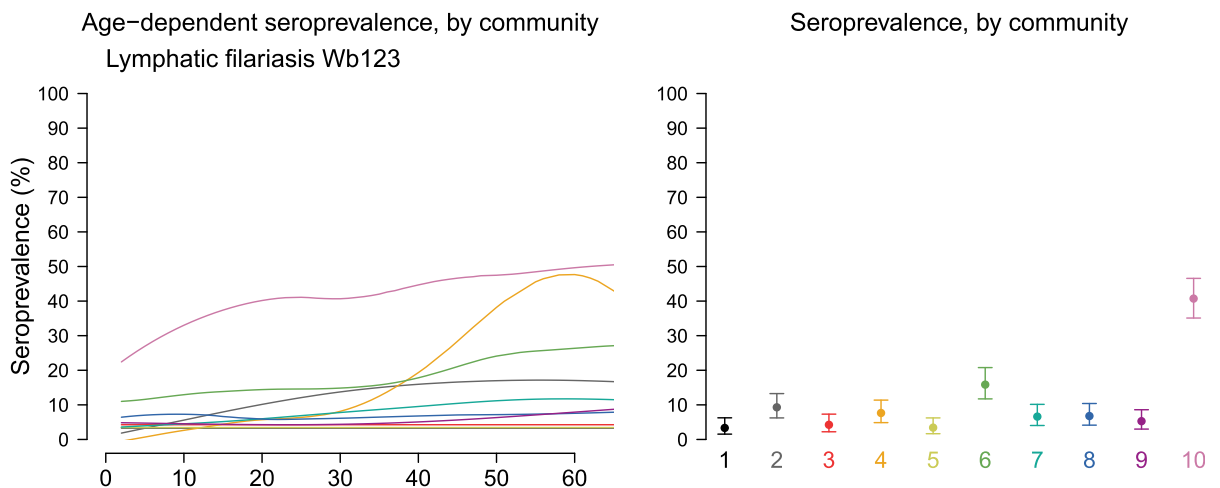

Lymphatic filariasis Bm14
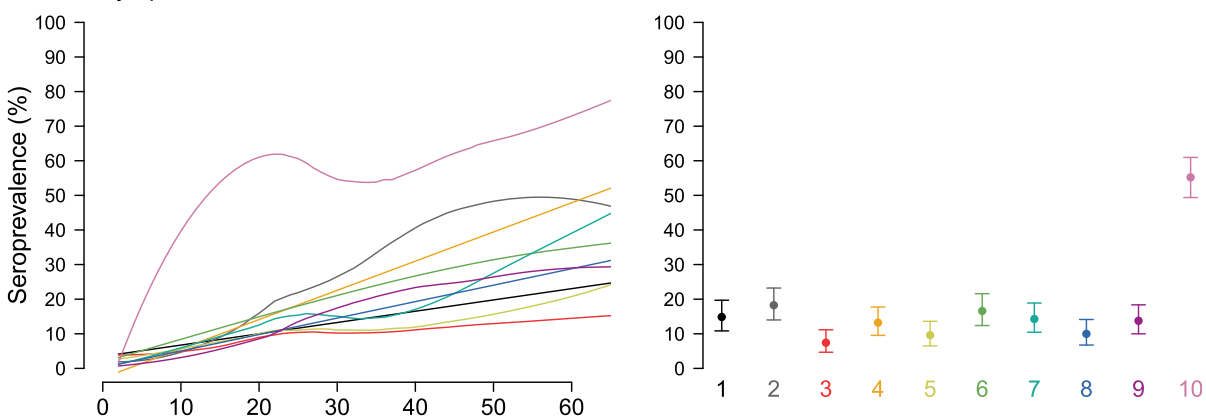

Lymphatic filariasis Bm33
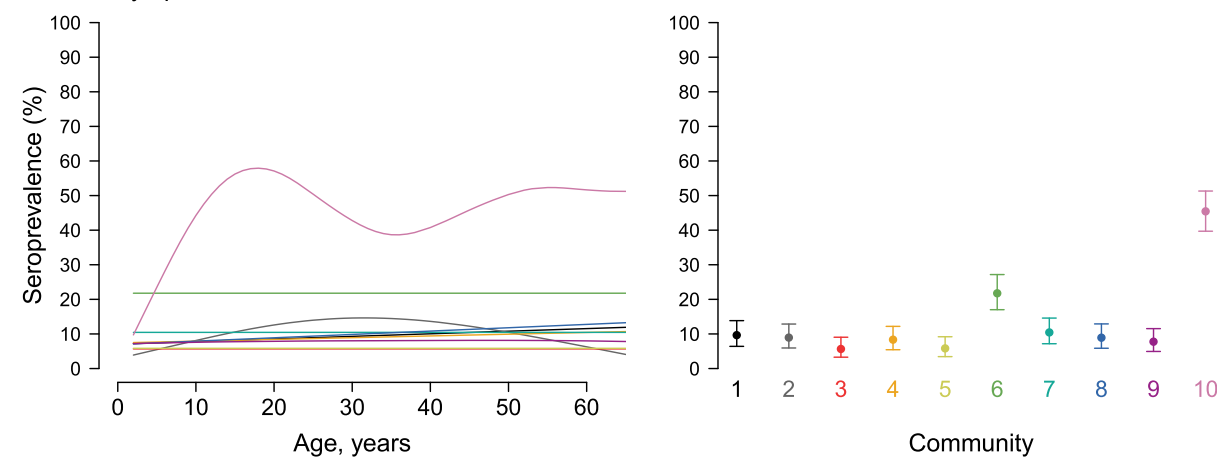

$\begin{array}{lll}\text { Taita Taveta } & \text { Kwale } & \text { Kilifi } \\ \text { 1 Kimorigo } & \text { 2 Makwenyeni } & 5 \text { Kinarani } \\ & \text { 3 Mirihini } & 6 \text { Jaribuni } \\ & 4 \text { Mwadimu } & \text { 7 Masindeni }\end{array}$

$\begin{array}{ll}\text { Tana River } & \text { Lamu } \\ 8 \text { Mikinduni } & 10 \text { Ndau } \\ 9 \text { Kipini } & \end{array}$

FIGURE 2. Lymphatic filariasis antibody age-dependent seroprevalence and overall means, stratified by community in Kenya's coastal region, 2015. Community-level mean seroprevalence is age-adjusted and error bars represent $95 \%$ Cls. Supplemental Figure 2 is an extended version of this figure that also includes mean antibody levels. Created with script: https://osf.io/5zkxw. This figure appears in color at www.ajtmh.org.

than in other communities in Kilifi $(P<0.0001$, Figure 3). Mean antibody responses against $P$. malariae MSP- $1_{19}$ antigen also increased with age and were highest in Jaribuni $(P<0.0001)$, but very low in Ndau Island and Kipini communities $(P<0.0001$ for difference with other communities).

Antibody responses against $S$. mansoni $\mathrm{Sm} 25$ recombinant antigen were primarily detected in Kimorigo community in Taita-Taveta County, and the seroprevalence increased gradually with age, reaching a peak at around 25 years of age (Figure 4). However, although antibody responses to S. mansoni SEA antigen also increased with age in Kimorigo community and mean seroprevalence was higher, there were some responses against this antigen in many other communities. Compared with the Sm25 recombinant antigen, the $S$. mansoni SEA antigen may have limited application in serosurveillance surveys because of crossreactivity.

Steady increases in S. stercoralis NIE seroprevalence with age were observed and community-level mean seroprevalence ranged between 3\% and 26\% (Figure 5). There was heterogeneity in age-dependent Ascaris $\mathrm{Hb}$ seroprevalence patterns across communities, with seroprevalence increasing with age in some communities and decreasing with age in others (Figure 5).

Immune responses to vaccine-preventable diseases. Immune response against measles MV-N antigen increased with age, but two communities in Kwale County (Mirihini and Mwadimu) had < $90 \%$ seroprotection (Figure 6). Immune responses to diphtheria toxoid were relatively higher among children but waned slightly around the ages of 30-40 years 

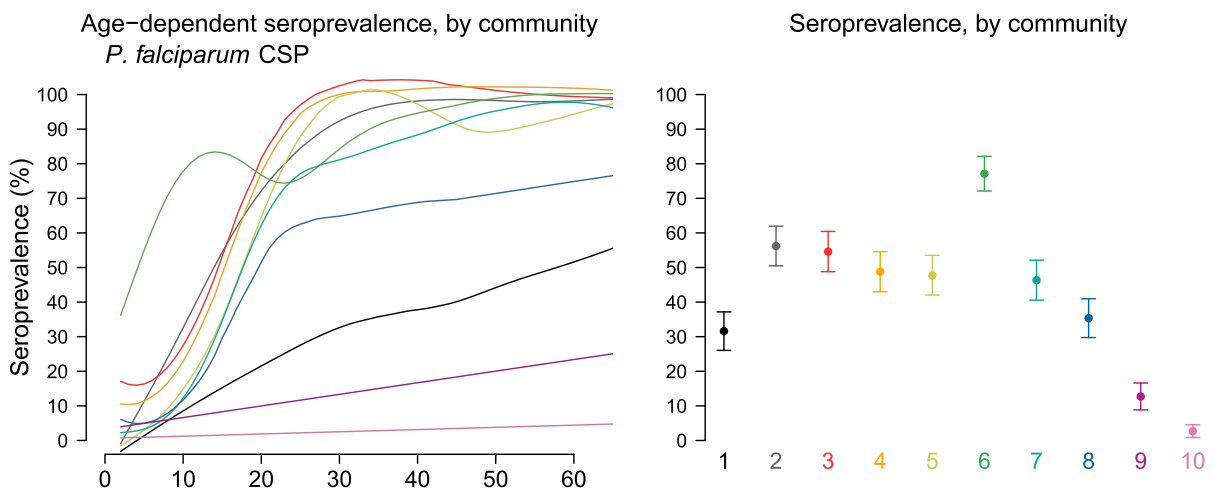

P. falciparum MSP-1
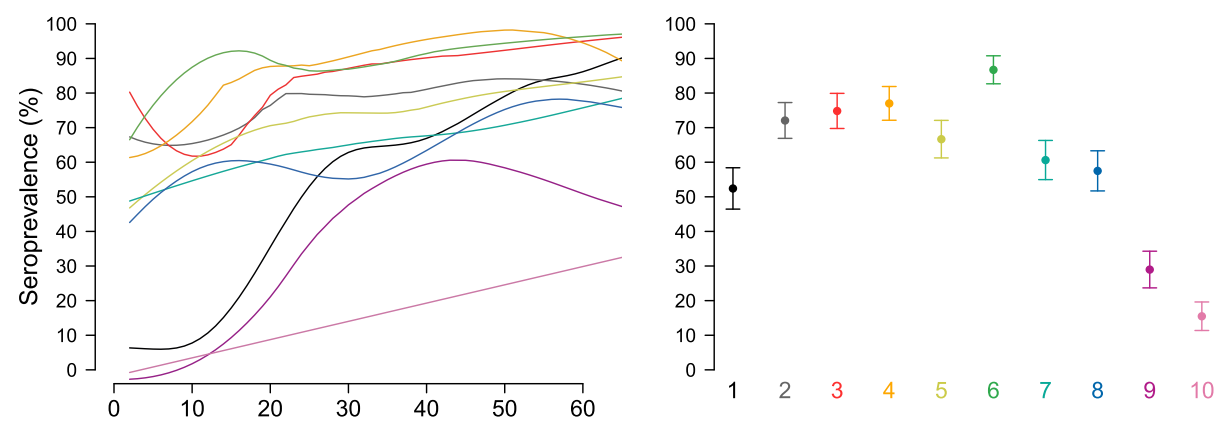

P. malariae MSP-1
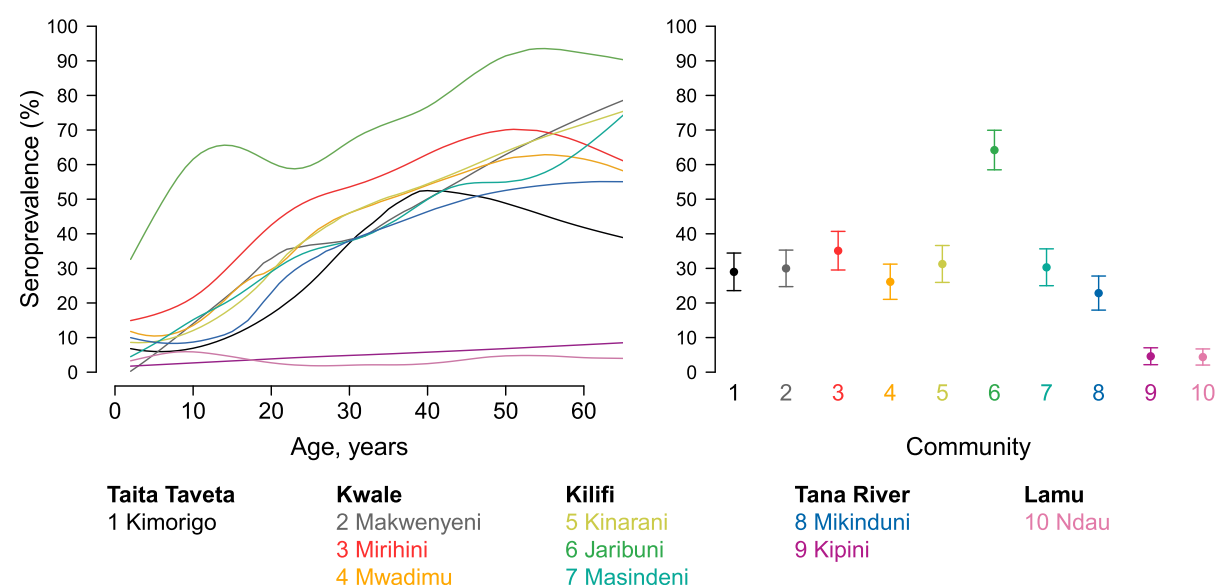

Tana River Lamu

8 Mikinduni $\quad 10 \mathrm{Ndau}$

9 Kipini

FIGURE 3. Malarial antibody age-dependent seroprevalence and overall means, stratified by community in Kenya's coastal region, 2015. Community-level mean seroprevalence is age-adjusted and error bars represent $95 \% \mathrm{Cls}$. Supplemental Figure 3 is an extended version of this figure that also includes mean antibody levels. Created with script: https://osf.io/kzfd3. This figure appears in color at www.ajtmh.org.

before increasing slightly. Generally, diphtheria seroprotection ranged between $22 \%$ and $44 \%$ across communities, and partial protection (defined as responses of $0.01-0.099 \mathrm{IU} / \mathrm{mL}$ ) ranged between $70 \%$ and $88 \%$ across communities. Immune responses against tetanus toxoid decreased by age in all communities until around 15 years when the levels increased again. However, tetanus seroprotection was lower in all three communities in Kwale County.

\section{DISCUSSION}

Antibodies can provide valuable information about exposure to pathogens and can be helpful for characterizing transmission dynamics in an area to help prioritize where and what interventions may be considered. ${ }^{24,45}$ This study provides an important proof of concept for how the value of existing epidemiological surveillance activities could dramatically be increased using small volumes of blood collected on a filter paper and analyzed using a single multiplex laboratory assay and novel data analysis techniques.

The LF survey in the coastal region of Kenya, which provided the opportunity to collect information for this study, demonstrated that Ndau Island in Lamu County had the highest prevalence of CFA by ICT. ${ }^{17}$ The antifilarial antibody measurements assessed by the MBA platform closely aligned with the CFA results. Ndau Island had the highest levels of antibody responses to all three recombinant filarial antigens, which confirms the observation that LF transmission is presently higher in Ndau Island than in the other communities. Previous studies have demonstrated a spatial relationship 
Age-dependent seroprevalence, by community

\section{S. mansoni SEA}

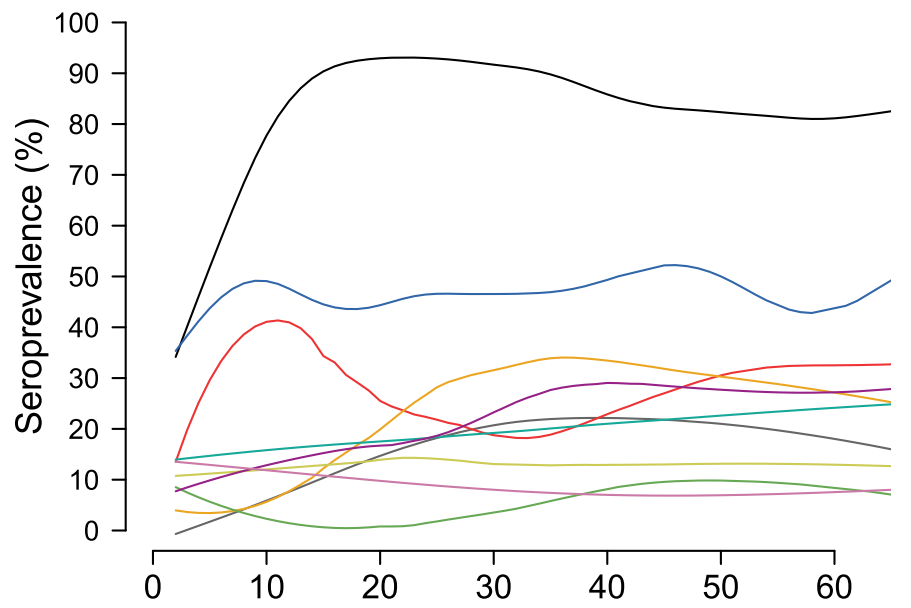

\section{S. mansoni Sm25}

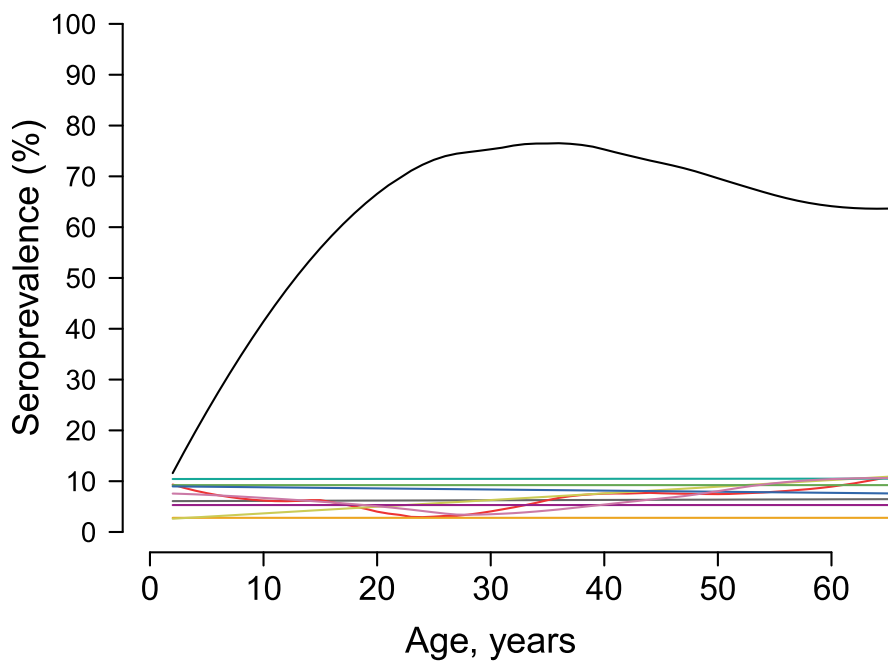

\section{Kwale}

2 Makwenyeni

3 Mirihini

4 Mwadimu
Kilifi

5 Kinarani

6 Jaribuni

7 Masindeni
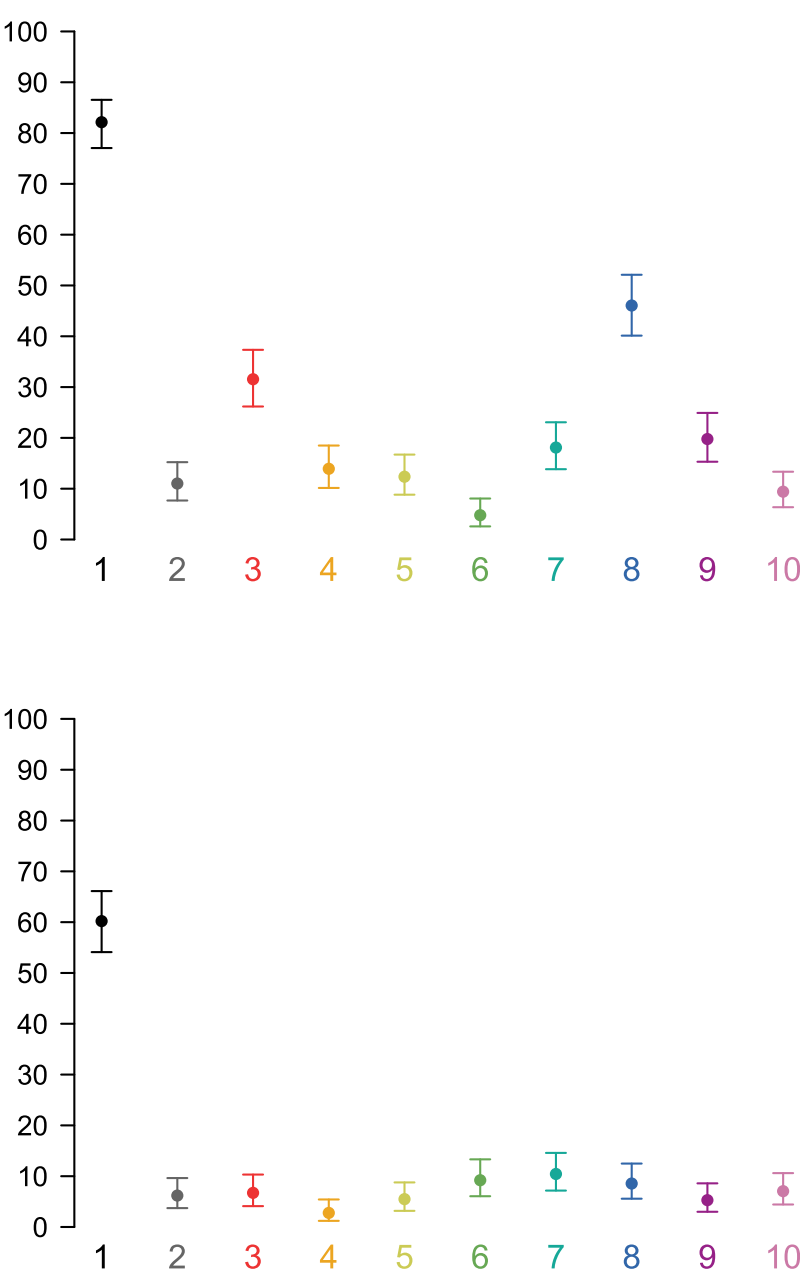

Community

Tana River

8 Mikinduni

Lamu

9 Kipini

FIGURE 4. Schistosomiasis antibody age-dependent seroprevalence and overall means, stratified by community in Kenya's coastal region, 2015. Community-level mean seroprevalence is age-adjusted and error bars represent $95 \%$ Cls. Supplemental Figure 4 is an extended version of this figure that also includes mean antibody levels. Created with script: https://osf.io/tpcg7. This figure appears in color at www.ajtmh.org.

between antibody-positive individuals and infected persons. ${ }^{46}$ The high seroprevalence rates in Ndau, especially among children, are consistent with the conclusion that transmission may be ongoing and not yet halted by the MDA campaign.

Antibody responses against Bm14 antigen continued to increase with age in all villages, which may have been an indication of cumulative exposure to $W$. bancrofti, and also likely reflects historic transmission. Generally, antibody responses against the three recombinant filarial antigens were higher among CFA-positive individuals than among CFA-negative persons although the difference was relatively smaller for Bm33 (see Supplemental Figure 7). Results from a recent study in American Samoa demonstrated that polymerase chain reactionpositive pools of LF vector mosquitoes were statistically significant predictors of seropositivity for Wb123 but not Bm14, suggesting Wb123 could be an indicator of ongoing transmission. ${ }^{47}$ Longitudinal studies in areas of intense LF transmission have shown that children acquire infections early in life. ${ }^{48,49}$ In addition, previous studies have demonstrated that antibody response against infective-stage filarial larvae antigen $\mathrm{Wb123}$ is a specific measure of $W$. bancrofti infection, and reduction in both antibody prevalence and transmission is seen most clearly in young children. ${ }^{50,51}$ Quantitative antifilarial antibody responses among youngest children (aged 2-5 years and 6-10 years) provided much higher resolution distinctions between communities compared with seroprevalence using the same antigens or the ICT test (Supplemental Figure 8) - a result consistent with a recent analysis across diverse pathogens in 
Age-dependent seroprevalence, by community S. stercoralis NIE

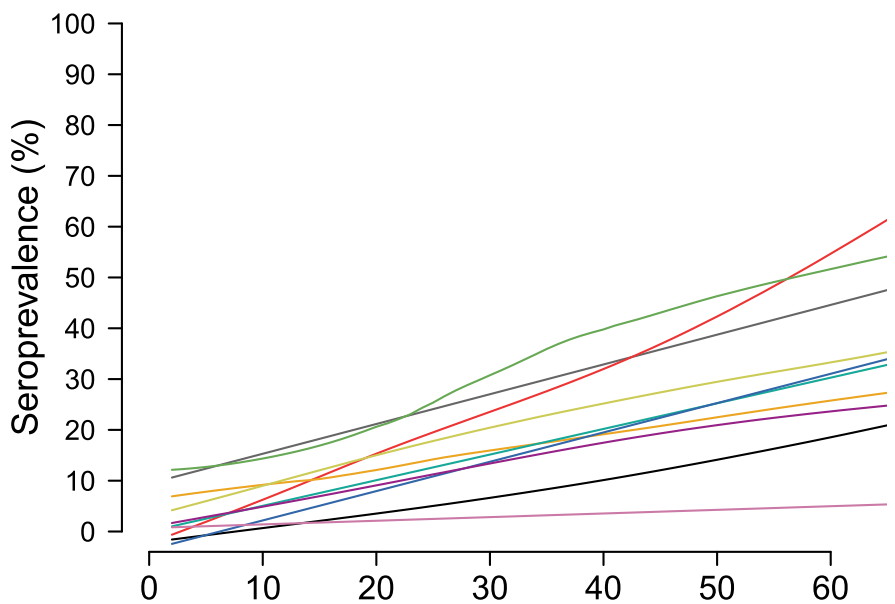

Ascaris spp. AsHb

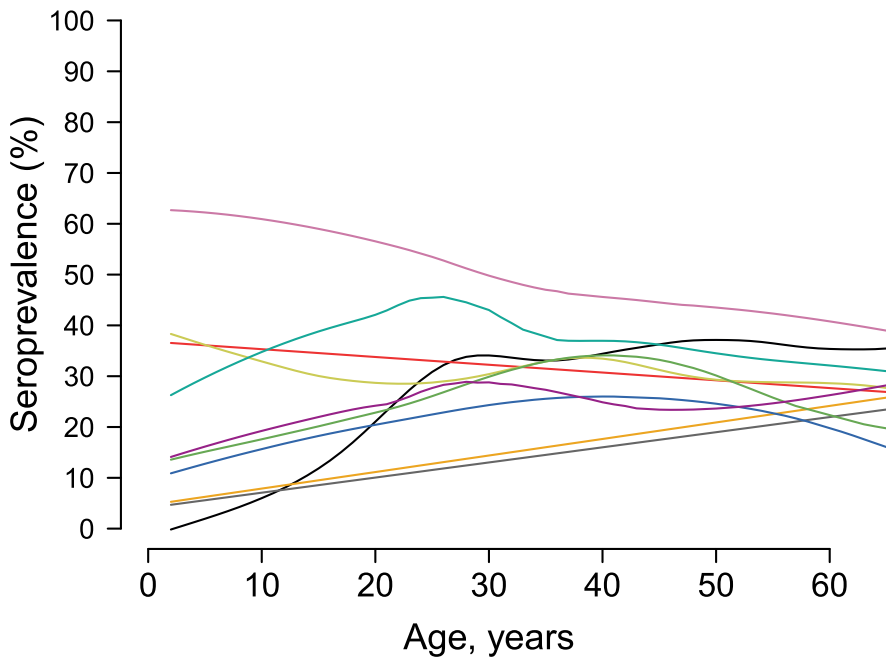

Taita Taveta

1 Kimorigo

Kwale
2 Makwenyeni
3 Mirihini
4 Mwadimu

Kwale

4. Mwadimu
Kilifi

5 Kinarani

6 Jaribuni

7 Masindeni
Seroprevalence, by community

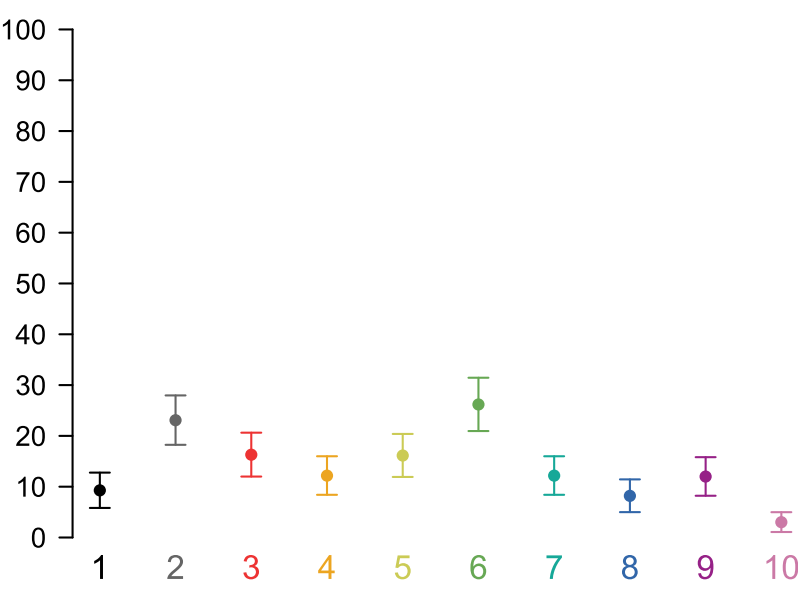

FIGURE 5. Age-dependent seroprevalence and overall mean for antibodies to Strongyloides stercoralis and Ascaris spp. stratified by community in Kenya's coastal region, 2015. Community-level mean seroprevalence is age-adjusted and error bars represent $95 \%$ Cls. Supplemental Figure 5 is an extended version of this figure that also includes mean antibody levels. Created with script: https://osf.io/j7ux3. This figure appears in color at www.ajtmh.org.

low-transmission settings where seropositive individuals are rare. ${ }^{18}$ The higher resolution of quantitative antibody responses compared with seroprevalence, particularly when measured in small sampling clusters, suggests that quantitative antibody levels could serve as an important and more sensitive indicator of recent exposure in sentinel populations of young children and may be a valuable tool for surveillance in the context of LF elimination programs. ${ }^{20}$ Thus, combined measurement of these markers may be suitable for characterization of LF transmission settings, particularly toward the end of the program when the infection prevalence is very low.

There was high heterogeneity in malaria seroprevalence among the study communities, with Kwale and Kilifi counties generally showing relatively higher malaria transmission than the other three counties. The community mean seroprevalence values suggested that both $P$. falciparum and $P$. malariae transmission were highest in Jaribuni community in Kilifi County. These differences may reflect environmental heterogeneity in malaria larval breeding sites, and Jaribuni may be a hot spot for malaria transmission. A previous study in Kilifi and Kwale counties identified the primary vectors of malaria along the coast of Kenya to include Anopheles funestus and three members of the An. gambiae complex: An. gambiae s.s., An. arabiensis, and $A n$. merus. ${ }^{52}$ The study also showed that relatively high malaria parasite prevalence can occur at low and even 

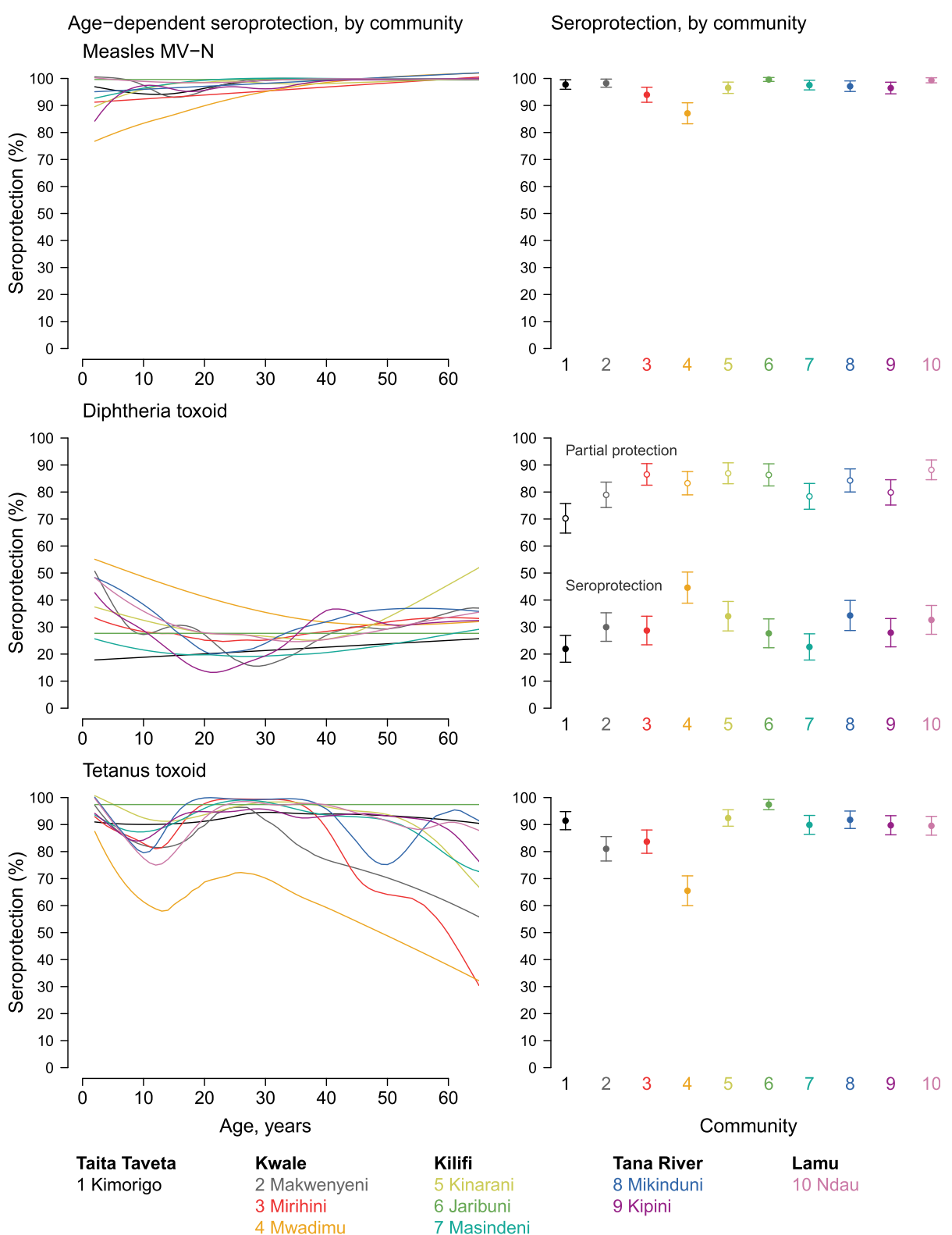

FIGURE 6. Age-dependent seroprotection and overall seroprotection for measles, diphtheria, and tetanus stratified by community in Kenya's coastal region, 2015. Community-level seroprotection is age-adjusted and error bars represent 95\% Cls. For diphtheria, we included separate community-level estimates of seroprotection (MFI-bg > 4,393 corresponding to $0.1 \mathrm{lU} / \mathrm{mL}$ ) and partial protection (MFI-bg > 183 corresponding to $0.01 \mathrm{IU} / \mathrm{mL}$ ). Supplemental Figure 6 is an extended version of this figure that also includes mean antibody levels. Created with script: https://osf.io/ qrkhm. This figure appears in color at www.ajtmh.org.

non-detectable levels of entomological inoculation rates (EIR), suggesting that measurement of EIR may be a relatively insensitive indicator of malaria transmission in some settings. Although malaria parasite prevalence and/or EIR have traditionally been used for reporting malaria transmission intensity, ${ }^{53}$ serological markers have increasingly been recognized as useful indicators for estimating malaria transmission intensity, which is key for assessing the impact of control interventions. ${ }^{54-57}$ Because of the longevity of the specific antibody response, seroprevalence reflects cumulative exposure and, thus, is less affected by seasonality or unstable transmission. ${ }^{58}$

In Kenya, Schistosoma haematobium is highly endemic along the coast where human exposure occurs primarily at pond and stream snail habitats..$^{9,59,60}$ The absence of S. mansoni from most of the Kenyan coastal region is attributable to the absence of the Biomphalaria spp. intermediatehost snails. ${ }^{61}$ In Mikinduni community, along the lower Tana River, crude antigen SEA antibody responses were observed, but $S$. mansoni-specific Sm25 responses were lacking. By contrast, Taveta area in Taita-Taveta County is known to be endemic for both $S$. haematobium and S. mansoni infections, ${ }^{62,63}$ and this is reflected in the high SEA and Sm25 antibody responses we observed in Kimorigo, a community located on the banks of the shallow freshwater Lake Jipe. The absence of S. mansoni species-specific antibody responses to Sm25 recombinant antigen in all of the communities except Kimorigo confirms 
that $S$. mansoni infection is likely absent from the lower coastal areas. Thus, S. mansoni Sm25 recombinant antigen seems to be an excellent antigen for measuring antibody responses to S. mansoni infection, ${ }^{64}$ and SEA antigen likely detects antibody responses caused by both Schistosoma species by virtue of cross-reactivity.

The presence of responses to $S$. stercoralis NIE antigen is noteworthy because there has been little information on the geographic distribution of this helminth in Kenya due to diagnostic limitations. Copromicroscopic diagnostic methods commonly used in soil-transmitted helminthiasis prevalence studies are inadequate for $S$. stercoralis detection, ${ }^{65}$ and thus its distribution in many areas is unknown. Concentration methods, namely, the Baermann technique and Koga agar plate culture, have better but still unsatisfactory sensitivity. ${ }^{66}$ A study using NIE serology in Argentina found no cross-reactivity between $S$. stercoralis and infections with $A$. lumbricoides, hookworms, or Hymenolepis nana, and the presence of other helminths in the stool did not affect the $S$. stercoralis-specific antibody responses. ${ }^{67}$ A study comparing five serologic tests identified NIE-luciferase immunoprecipitation system to be the most accurate assay for the diagnosis of $S$. stercoralis infection. ${ }^{68}$ Previous studies using the recombinant NIE have documented high seroprevalence of $S$. stercoralis infection in remote Australian Indigenous communities and suggest that collection of DBSs may be a useful approach for field diagnosis of S. stercoralis seroprevalence. ${ }^{69,70}$ This study, therefore, provides evidence for possible low-level transmission of S. stercoralis in coastal Kenya as the seroprevalence varies from community to community. Community mean antibody responses to the Ascaris $\mathrm{Hb}$ native antigen and seroprevalence exhibited high heterogeneity among the study communities. A population-based study in Indonesia has shown that an assay for antibodies to Ascaris $\mathrm{Hb}$ is useful for assessing transmission of Ascaris infections, and community antibody rates decreased rapidly following MDA of anthelmintic drugs. The decrease was also found to reflect reduced egg excretion at the community level. ${ }^{38}$

Vaccination is one of the most cost-effective public health interventions available, and the epidemiology and burden of VPDs vary by country and by region partly because of differences in vaccine uptake. ${ }^{71}$ This multiplex-integrated serosurveillance study identified heterogeneity in serologic antibody levels against measles, diphtheria, and tetanus antigens. Our study demonstrates a need for regularly monitoring serological responses to vaccination programs in resource-poor settings where coverage may be low.

Some of the limitations of this study are somewhat similar to those highlighted previously. ${ }^{24}$ This was a preliminary, proofof-concept study, and, because of the lack of direct comparison of results with those obtained from already validated commercial assays, the MBA described here was not intended to replace diagnostic tests that are presently available for use by disease control/elimination programs. Also, serological studies are traditionally faced with the challenge of establishing diagnostic cutoff points, especially when wellcharacterized positive and negative serum samples are not available. Nonetheless, the Gaussian mixture models applied in this study led to cutoff values that were very similar to those derived through ROC curves or from mean plus three SD calculations for malaria, LF, and helminth antibody responses
(Figure 1). This result is consistent with a recent, multicountry comparison of cutoff methodology for trachoma antibodies ${ }^{72}$ and supports the use of finite mixture models to identify seropositivity cutoffs in studies without access to panels of known positive and negative specimens. For pathogens where cutoff values fall in the center of a unimodal distribution and it is more difficult to distinguish seropositive and seronegative groups (e.g., A. suum $\mathrm{Hb}$ in Figure 1), the use of community mean antibody levels avoids the requirement of choosing a cutoff, and observed antibody response patterns were very consistent with seroprevalence estimates across all of the antibodies tested in this study (Supplemental Figures 2-6). Another limitation of this study is potential for helminth antibody cross-reactivity, particularly because the MBA measured total IgG antibody rather than the more specific IgG4. Because the coastal area has a typical tropical climate, it is likely that a plethora of pathogens are coincident, some with potentially cross-reactive antigens. A previous study reported that cross-reactivity of the Ascaris $\mathrm{Hb}$ native antigen with hookworm and possibly S. stercoralis and Toxocara spp. limited its value in serology if one is interested in ascariasis alone. ${ }^{38}$ Thus, further studies are required to identify sensitive and specific recombinant antigens that could be used with more confidence in serological assays. A final limitation is that the multiplex assay we used in our study is not commercially available. In practice, it will be more realistic for programs to incorporate integrated antibody surveillance into their surveys when bead-based antibody assays can be purchased in a ready-to-use kit format, especially if the assays can be analyzed with instruments that do not rely on flow cytometry for fluorescent signal detection. Commercial kits with good quality control would potentially also help standardize the assays across laboratories.

Despite these limitations, this study successfully used a single multiplex-integrated serological assay and analysis methodology to measure antibody levels against several pathogens. There was no need to run separate assays for each pathogen, and we did not need to develop different mathematical models for each pathogen to compare exposure across communities and counties. The study highlighted overlap in pathogen burden that would not necessarily have been detected through single-disease surveillance. For example, Ndau Island was found to have not only the highest LF seroprevalence but also highest Ascaris seroprevalence, thus supporting integrated control of these two helminths. Interestingly, Ndau had almost no evidence for $P$. falciparum malaria transmission. On the other hand, Jaribuni community was found to stand out in terms of malaria, LF, and Strongyloides. Multiplex serosurveillance has the potential to enable us to look across diseases for opportunities for integrated control, thus providing synergy to global public health initiatives.

\section{CONCLUSION}

This study highlighted the utility of the MBA platform for integrated serosurveillance of biomarkers of diseases of public health importance. The multiplex-integrated serologic assay has the potential to become an invaluable complementary epidemiologic tool for integrated monitoring of trends in endemicity of diseases of public health importance and the effectiveness of public health control programs. 
Received May 11, 2019. Accepted for publication September 11, 2019.

Published online November 25, 2019.

Note: Supplemental figures appear at www.ajtmh.org.

Acknowledgments: We would like to thank the County Health Departments of Taita-Taveta, Kwale, Kilifi, Tana River, and Lamu for supporting the survey, including provision of laboratory technicians and local transportation for the survey teams; the communities of the selected sentinel sites and their local leaders for the cooperation and assistance; Patrick Lammie (CDC) and Simon Brooker (LSHTM) for their useful comments and suggestions throughout the study; members of the Vaccine Preventable Disease Branch (CDC) including Sun Bae Sowers for sharing measles PRNT data; T. Nutman $(\mathrm{NIH}$, Bethesda, MD), E. Secor (CDC, Atlanta, GA), and P. Geldhof (Ghent University, Gent, Belgium) for reagents; and the Kenya Medical Research Institute (KEMRI) for providing scientific leadership and oversight for this study.

Financial support: The collection of DBS samples used in this study work was supported by a grant provided by the WHO Regional Office for Africa (WHO-AFRO) to the Kenya Medical Research Institute (KEMRI) through the WHO country office. The Task Force for Global Health through NTD Support Center, United States, provided funds for multiplex bead assay laboratory work. B. F. A. was supported by National Institutes of Health grant K01-Al119180.

Disclaimer: The use of trade names is for identification only and does not imply endorsement by the Public Health Service or by the U.S. Department of Health and Human Services. The findings and conclusions in this report are those of the authors and do not necessarily represent the official position of the Centers for Disease Control and Prevention or any other institution.

Authors' addresses: Sammy M. Njenga and Henry M. Kanyi, Eastern and Southern Africa Centre of International Parasite Control, Kenya Medical Research Institute, Nairobi, Kenya, E-mails: sammynjenga@ gmail.com and kanyi2009@gmail.com. Benjamin F. Arnold, Division of Epidemiology, University of California, Berkeley, CA, E-mail: benarnold@berkeley.edu. Sultani H. Matendechero, Ministry of Health, Nairobi, Kenya, E-mail: hadleysultani@gmail.com. Joyce K. Onsongo, World Health Organization Country Office, Nairobi, Kenya, E-mail: onsongoj@who.int. Kimberly Y. Won, Centers for Disease Control and Prevention, Atlanta, GA, E-mail: kfw7@cdc.gov. Jeffrey W. Priest, Centers for Disease Control and Prevention, Atlanta, GA, E-mail: jip8@cdc.gov.

This is an open-access article distributed under the terms of the Creative Commons Attribution License, which permits unrestricted use, distribution, and reproduction in any medium, provided the original author and source are credited.

\section{REFERENCES}

1. Brooker S, Clements ACA, Hotez PJ, Hay SI, Tatem AJ, Bundy DAP, Snow RW, 2006. The co-distribution of Plasmodium falciparum and hookworm among African schoolchildren. Malar J 5: 1-8.

2. Hotez PJ, Molyneux DH, Fenwick A, Ottesen E, Ehrlich Sachs S, Sachs JD, Bundy D, 2006. Incorporating a rapid-impact package for neglected tropical diseases with programs for HIV/ AIDS, tuberculosis, and malaria. PLoS Med 3: e102.

3. Molyneux DH, Hotez PJ, Fenwick A, 2005. "Rapid-impact interventions": how a policy of integrated control for Africa's neglected tropical diseases could benefit the poor. PLoS Med 2: 1064-1070.

4. Hürlimann E, Yapi RB, Houngbedji CA, Schmidlin T, Kouadio BA, Silué KD, Ouattara M, N'Goran EK, Utzinger J, Raso G, 2014. The epidemiology of polyparasitism and implications for morbidity in two rural communities of Côte d'Ivoire. Parasit Vectors 7: 81.

5. Keiser J, N'Goran EK, Traoré M, Lohourignon KL, Singer BH, Lengeler C, Tanner M, Utzinger J, 2002. Polyparasitism with Schistosoma mansoni, geohelminths, and intestinal protozoa in rural Côte d'Ivoire. J Parasitol 88: 461-466.

6. Raso $\mathrm{G}$ et al., 2004. Multiple parasite infections and their relationship to self-reported morbidity in a community of rural Cote d'Ivoire. Int J Epidemiol 33: 1092-1102.
7. Moraga $P$ et al., 2015. Modelling the distribution and transmission intensity of lymphatic filariasis in sub-Saharan Africa prior to scaling up interventions: integrated use of geostatistical and mathematical modelling. Parasit Vectors 8: 560.

8. Munywoki PK, Ohuma EO, Ngama M, Bauni E, Scott JAG, Nokes DJ, 2013. Severe lower respiratory tract infection in early infancy and pneumonia hospitalizations among children, Kenya. Emerg Infect Dis 19: 223-229.

9. Njenga SM, Mwandawiro CS, Muniu E, Mwanje MT, Haji FM, Bockarie MJ, 2011. Adult population as potential reservoir of NTD infections in rural villages of Kwale district, Coastal Kenya: implications for preventive chemotherapy interventions policy. Parasit Vectors 4: 175.

10. Okiro EA, Hay SI, Gikandi PW, Sharif SK, Noor AM, Peshu N, Marsh K, Snow RW, 2007. The decline in paediatric malaria admissions on the coast of Kenya. Malar J 6: 151.

11. WHO, 2011. Monitoring and Epidemiological Assessment of Mass Drug Administration in the Global Programme to Eliminate Lymphatic Filariasis: A Manual for National Elimination Programmes. Geneva, Switzerland: World Health Organization.

12. Stolk WA, Swaminathan S, van Oortmarssen GJ, Das PK, Habbema JDF, 2003. Prospects for elimination of bancroftian filariasis by mass drug treatment in Pondicherry, India: a simulation study. J Infect Dis 188: 1371-1381.

13. Michael E, Bundy DA, Grenfell BT, 1996. Re-assessing the global prevalence and distribution of lymphatic filariasis. Parasitology 112: 409-428.

14. Sodahlon YK, Dorkenoo AM, Morgah K, Nabiliou K, Agbo K, Miller R, Datagni M, Seim A, Mathieu E, 2013. A success story: togo is moving toward becoming the first sub-Saharan African nation to eliminate lymphatic filariasis through mass drug administration and countrywide morbidity alleviation. PLoS Negl Trop Dis 7: e2080.

15. WHO, 2017. Togo: First Country in Sub-saharan Africa to Eliminate Lymphatic Filariasis. Geneva, Switzerland: World Health Organization. Available at: http://www.who.int/neglected diseases/news/Togo_saying_goodbye_lymphatic_filariasis/en/. Accessed May 20, 2017.

16. Njenga SM, Mwandawiro CS, Wamae CN, Mukoko DA, Omar AA, Shimada M, Bockarie MJ, Molyneux DH, 2011. Sustained reduction in prevalence of lymphatic filariasis infection in spite of missed rounds of mass drug administration in an area under mosquito nets for malaria control. Parasit Vectors 4: 90.

17. Njenga SM et al., 2017. Assessment of lymphatic filariasis prior to re-starting mass drug administration campaigns in coastal Kenya. Parasit Vectors 10: 99.

18. Arnold BF, van der Laan MJ, Hubbard AE, Steel C, Kubofcik J, Hamlin KL, Moss DM, Nutman TB, Priest JW, Lammie PJ, 2017. Measuring changes in transmission of neglected tropical diseases, malaria, and enteric pathogens from quantitative antibody levels. PLoS Negl Trop Dis 11: e0005616.

19. Wipasa J, Suphavilai C, Okell LC, Cook J, Corran PH, Thaikla K, Liewsaree W, Riley EM, Hafalla JCR, 2010. Long-lived antibody and $B$ cell memory responses to the human malaria parasites, Plasmodium falciparum and Plasmodium vivax. PLoS Pathog 6: e1000770.

20. Hamlin KL, Moss DM, Priest JW, Roberts J, Kubofcik J, Gass K, Streit TG, Nutman TB, Eberhard ML, Lammie PJ, 2012. Longitudinal monitoring of the development of antifilarial antibodies and acquisition of Wuchereria bancrofti in a highly endemic area of Haiti. PLoS Negl Trop Dis 6: e1941.

21. Lammie PJ, Moss DM, Brook Goodhew E, Hamlin K, Krolewiecki A, West SK, Priest JW, 2012. Development of a new platform for neglected tropical disease surveillance. Int J Parasitol 42: 797-800.

22. Moss DM, Priest JW, Boyd A, Weinkopff T, Kucerova Z, Beach MJ, Lammie PJ, 2011. Multiplex bead assay for serum samples from children in Haiti enrolled in a drug study for the treatment of lymphatic filariasis. Am J Trop Med Hyg 85: 229-237.

23. Priest JW, Moss DM, Visvesvara GS, Jones CC, Li A, Isaac-Renton $\mathrm{JL}, 2010$. Multiplex assay detection of immunoglobulin $\mathrm{G}$ antibodies that recognize Giardia intestinalis and Cryptosporidium parvum antigens. Clin Vaccine Immunol 17: 1695-1707.

24. Priest JW et al., 2016. Integration of multiplex bead assays for parasitic diseases into a national, population-based serosurvey of women 15-39 years of age in Cambodia. PLoS Negl Trop Dis 10: e0004699. 
25. Arnold BF, Priest JW, Hamlin KL, Moss DM, Colford JM Jr., Lammie PJ, 2014. Serological measures of malaria transmission in Haiti: comparison of longitudinal and crosssectional methods. PLoS One 9: e93684.

26. Rogier E, Moss DM, Chard AN, Trinies V, Doumbia S, Freeman MC, Lammie PJ, 2016. Evaluation of immunoglobulin G responses to Plasmodium falciparum and Plasmodium vivax in Malian school children using multiplex bead assay. Am J Trop Med Hyg 96: 312-318.

27. Moss DM, Montgomery JM, Newland SV, Priest JW, Lammie PJ, 2004. Detection of cryptosporidium antibodies in sera and oral fluids using multiplex bead assay. J Parasitol 90: 397-404.

28. Rascoe LN, Price C, Shin SH, McAuliffe I, Priest JW, Handali S, 2015. Development of Ss-NIE-1 recombinant antigen based assays for immunodiagnosis of strongyloidiasis. PLoS Negl Trop Dis 9: e0003694.

29. Rogier E et al., 2015. Multiple comparisons analysis of serological data from an area of low Plasmodium falciparum transmission. Malar J 14: 436.

30. Won KY et al., 2017. Multiplex serologic assessment of schistosomiasis in western Kenya: antibody responses in preschool aged children as a measure of reduced transmission. Am J Trop Med Hyg 96: 1460-1467.

31. Hummel KB, Erdman DD, Heath J, Bellini WJ, 1992. Baculovirus expression of the nucleoprotein gene of measles virus and utility of the recombinant protein in diagnostic enzyme immunoassays. J Clin Microbiol 30: 2874-2880.

32. Scobie HM et al., 2016. Tetanus immunity among women aged 15 to 39 years in Cambodia: a national population-based serosurvey, 2012. Clin Vaccine Immunol 23: 546-554.

33. Priest JW, Plucinski MM, Huber CS, Rogier E, Mao B, Gregory CJ, Candrinho B, Colborn J, Barnwell JW, 2018. Specificity of the IgG antibody response to Plasmodium falciparum, Plasmodium vivax, Plasmodium malariae, and Plasmodium ovale MSP119 subunit proteins in multiplexed serologic assays. Malar $\mathrm{J}$ 17: 417.

34. Benitez A, Priest JW, Ehigiator HN, McNair N, Mead JR, 2011. Evaluation of DNA encoding acidic ribosomal protein P2 of Cryptosporidium parvum as a potential vaccine candidate for cryptosporidiosis. Vaccine 29: 9239-9245.

35. Ballou WR, Rothbard J, Wirtz RA, Gordon DM, Williams JS, Gore RW, Schneider I, Hollingdale MR, Beaudoin RL, Maloy WL, 1985. Immunogenicity of synthetic peptides from circumsporozoite protein of Plasmodium falciparum. Science 228: 996-999.

36. Dame JB, Williams JL, McCutchan TF, Weber JL, Wirtz RA, Hockmeyer WT, Maloy WL, Haynes JD, Schneider I, Roberts D, 1984. Structure of the gene encoding the immunodominant surface antigen on the sporozoite of the human malaria parasite Plasmodium falciparum. Science 225: 593-599.

37. Vlaminck J, Nejsum P, Vangroenweghe F, Thamsborg SM, Vercruysse J, Geldhof P, 2012. Evaluation of a serodiagnostic test using Ascaris suum haemoglobin for the detection of roundworm infections in pig populations. Vet Parasitol 189: 267-273.

38. Vlaminck J, Supali T, Geldhof P, Hokke CH, Fischer PU, Weil GJ, 2016. Community rates of IgG4 antibodies to Ascaris haemoglobin reflect changes in community egg loads following mass drug administration. PLoS Negl Trop Dis 10: e0004532.

39. Borrow R, Balmer P, Roper MH, 2006. The Immunological basis for Immunization Series Module 3: Tetanus-Update 2006. Geneva, Switzerland: World Health Organization. Available at: http:// apps.who.int/iris/bitstream/10665/43687/1/9789241595551_ eng.pdf. Accessed September 15, 2017.

40. Kristiansen M, Aggerbeck H, Heron I, 1997. Improved ELISA for determination of anti-diphtheria and/or anti-tetanus antitoxin antibodies in sera. APMIS 105: 843-853.

41. Scheifele DW, Ochnio JJ, 2009. The Immunologic Basis for Immunization Series: Module 2: Diphtheria-Update 2009. Geneva, Switzerland: World Health Organization. Available at: http:// apps.who.int/iris/bitstream/10665/44094/1/9789241597869_ eng.pdf. Accessed September 15, 2017.

42. van Gageldonk PGM, von Hunolstein C, van der Klis FRM, Berbers GAM, 2011. Improved specificity of a multiplex immunoassay for quantitation of anti-diphtheria toxin antibodies with the use of diphtheria toxoid. Clin Vaccine Immunol 18: 1183-1186.

43. Bentley M, Christian PD, Cohen BJ, Heath A, 2006. Report of a Collaborative Study to Assess the Suitability of a Replacement for the 2nd International Standard for Anti-Measles Sera, WHO/ BS/06.2031. Geneva, Switzerland: World Health Organization. Available at: http://apps.who.int/iris/bitstream/10665/70612/1/ WHO_BS_06.2031_eng.pdf. Accessed September 15, 2017.

44. Benaglia T, Chauveau D, Hunter DR, Young DS, 2009. Mixtools: an R package for analyzing mixture models. J Stat Softw 32: $1-29$.

45. Lau CL, Won KY, Becker L, Soares Magalhaes RJ, Fuimaono S, Melrose W, Lammie PJ, Graves PM, 2014. Seroprevalence and spatial epidemiology of Lymphatic filariasis in American Samoa after successful mass drug administration. PLoS Negl Trop Dis 8: e3297.

46. Joseph H, Maiava F, Naseri T, Silva U, Lammie P, Melrose W, 2011. Epidemiological assessment of continuing transmission of lymphatic filariasis in Samoa. Ann Trop Med Parasitol 105: 567-578.

47. Lau CL, Won KY, Lammie PJ, Graves PM, 2016. Lymphatic filariasis elimination in American Samoa: evaluation of molecular xenomonitoring as a surveillance tool in the endgame. PLoS Negl Trop Dis 10: e0005108.

48. Witt C, Ottesen EA, 2001. Lymphatic filariasis: an infection of childhood. Trop Med Int Heal 6: 582-606.

49. Lammie PJ, Reiss MD, Dimock KA, Streit TG, Roberts JM, Eberhard ML, 1998. Longitudinal analysis of the development of filarial infection and antifilarial immunity in a cohort of Haitian children. Am J Trop Med Hyg 59: 217-221.

50. Kubofcik J, Fink DL, Nutman TB, 2012. Identification of Wb123 as an early and specific marker of Wuchereria bancrofti infection. PLoS Negl Trop Dis 6: e1930.

51. Steel C, Kubofcik J, Ottesen EA, Nutman TB, 2012. Antibody to the filarial antigen $\mathrm{Wb} 123$ reflects reduced transmission and decreased exposure in children born following single mass drug administration (MDA). PLoS Negl Trop Dis 6: e1940.

52. Mbogo CM et al., 2003. Spatial and temporal heterogeneity of anopheles mosquitoes and Plasmodium falciparum transmission along the Kenyan coast. Am J Trop Med Hyg 68: 734-742.

53. Pothin E, Ferguson NM, Drakeley CJ, Ghani AC, 2016. Estimating malaria transmission intensity from Plasmodium falciparum serological data using antibody density models. Malar J 15: 79.

54. Wong J et al., 2014. Serological markers for monitoring historical changes in malaria transmission intensity in a highly endemic region of western Kenya, 1994-2009. Malar J 13: 451.

55. Cook J, Reid H, lavro J, Kuwahata M, Taleo G, Clements A, McCarthy J, Vallely A, Drakeley C, 2010. Using serological measures to monitor changes in malaria transmission in Vanuatu. Malar J 9: 169.

56. Drakeley CJ et al., 2005. Estimating medium- and long-term trends in malaria transmission by using serological markers of malaria exposure. Proc Natl Acad Sci USA 102: 5108-5113.

57. Dewasurendra RL, Dias JN, Sepulveda N, Gunawardena GSA, Chandrasekharan N, Drakeley C, Karunaweera ND, 2017. Effectiveness of a serological tool to predict malaria transmission intensity in an elimination setting. BMC Infect Dis 17: 49.

58. Badu K et al., 2012. Marked variation in MSP-119 antibody responses to malaria in western Kenyan highlands. BMC Infect Dis 12: 50 .

59. Njaanake KH, Vennervald BJ, Simonsen PE, Madsen H, Mukoko DA, Kimani G, Jaoko WG, Estambale BB, 2015. Schistosoma haematobium and soil-transmitted helminths in Tana delta district of Kenya: infection and morbidity patterns in primary schoolchildren from two isolated villages. BMC Infect Dis 16: 57.

60. Clennon JA, King CH, Muchiri EM, Kariuki HC, Ouma JH, Mungai $P$, Kitron U, 2004. Spatial patterns of urinary schistosomiasis infection in a highly endemic area of coastal Kenya. Am J Trop Med Hyg 70: 443-448.

61. Brown DS, Jelnes JE, Kinoti GK, Ouma J, 1981. Distribution in Kenya of intermediate hosts of Schistosoma. Trop Geogr Med 33: 95-103.

62. Gouvras AN, Kariuki C, Koukounari A, Norton AJ, Lange CN, Ireri E, Fenwick A, Mkoji GM, Webster JP, 2013. The impact of single 
versus mixed Schistosoma haematobium and S. mansoni infections on morbidity profiles amongst school-children in Taveta, Kenya. Acta Trop 128: 309-317.

63. Thiongo FW, Ouma JH, 1987. Prevalence of schistosomes and other parasites in Taita division of Taita-Taveta district. East Afr Med J 64: 665-671.

64. Tsang VC, Hancock K, Kelly MA, Wilson BC, Maddison SE, 1983. Schistosoma mansoni adult microsomal antigens, a serologic reagent. II. Specificity of antibody responses to the S. mansoni microsomal antigen (MAMA). J Immunol 130: 1366-1370.

65. Steinmann P, ZhouX-N, Du Z-W, Jiang J-Y, Wang L-B, Wang X-Z, Li L-H, Marti H, Utzinger J, 2007. Occurrence of Strongyloides stercoralis in Yunnan province, China, and comparison of diagnostic methods. PLoS Negl Trop Dis 1: e75.

66. Glinz D, Silué KD, Knopp S, Lohourignon LK, Yao KP, Steinmann P, Rinaldi L, Cringoli G, N'Goran EK, Utzinger J, 2010. Comparing diagnostic accuracy of Kato-Katz, Koga agar plate, ether-concentration, and FLOTAC for Schistosoma mansoni and soil-transmitted helminths. PLoS Negl Trop Dis 4: e754.

67. Krolewiecki AJ et al., 2010. Improved diagnosis of Strongyloides stercoralis using recombinant antigen-based serologies in a community-wide study in northern Argentina. Clin Vaccine Immunol 17: 1624-1630.

68. Bisoffi $Z$ et al., 2014. Diagnostic accuracy of five serologic tests for Strongyloides stercoralis infection. PLoS Negl Trop Dis 8: e2640.

69. Kearns TM et al., 2017. Strongyloides seroprevalence before and after an ivermectin mass drug administration in a remote Australian aboriginal community. PLoS Negl Trop Dis 11: e0005607.

70. Mounsey K, Kearns T, Rampton M, Llewellyn S, King M, Holt D, Currie BJ, Andrews R, Nutman T, McCarthy J, 2014. Use of dried blood spots to define antibody response to the Strongyloides stercoralis recombinant antigen NIE. Acta Trop 138: 78-82.

71. Brenzel L, Wolfson LJ, Fox-Rushby J, Miller M, Halsey NA, 2006. Vaccine-Preventable Diseases. Jamison D, Breman J, Measham A, eds, 2nd edition. New York, NY: Oxford University Press. Available at: http://www.ncbi.nlm.nih.gov/pubmed/ 21250343. Accessed July 3, 2017.

72. Migchelsen SJ et al., 2017. Defining seropositivity thresholds for use in trachoma elimination studies. PLoS Negl Trop Dis 11: e0005230. 